\title{
A ESTRUTURA DA FUNÇÃO POÉTICA
}

\section{THE STRUCTURE OF THE POETIC FUNCTION}

\author{
MARCEla UlhôA Borges MAGALHÃES * \\ JoÃo BATISTA TOLEDO PRADO **
}

RESUMO: 0 presente artigo tem como objetivo realizar uma reflexão a respeito da estrutura profunda do signo poético por meio de uma investigação de cunho semiótico. A fim de que os resultados pretendidos sejam alcançados, faz-se necessário regressar aos princípios de base da semiótica francesa, cujos fundamentos principais encontram-se presentes no Curso de Linguística Geral, de Ferdinand de Saussure, e nos Prolegômenos a uma Teoria da Linguagem, de Louis Hjelmslev, até alcançar a obra de Algirdas Greimas, Jean-Marie Floch e Roman Jakobson, que serão fundamentais para o desenvolvimento da reflexão a respeito da natureza da função poética da linguagem. Do conjunto da obra desses autores, serão exploradas, principalmente, as noções de paralelismo entre os planos da linguagem, a de signo linguístico e a de semissimbolismo, que sugerem ser um caminho possível para compreender o funcionamento do signo poético e, consequentemente, para fornecer subsídio à análise de textos em que a função poética da linguagem predomina.

\footnotetext{
* Doutoranda da Unesp - Universidade Estadual Paulista - E-mail: marcelacfj@hotmail.com.

** Docente da Unesp - Universidade Estadual Paulista - E-mail: jbtprado@gmail.com.
} 
PALAVRAS-CHAVE: Função poética. Signo. Planos da linguagem. Semissimbolismo.

ABSTRACT: This paper aims to conduct a reflection on the deep structure of the poetic sign under a semiotic perspective. In order to accomplish that, it is necessary to go back first to some of the fundamental principles of the French semiotics, whose main foundations are present in Ferdinand de Saussure's Course in General Linguistics and in Louis Hjelmslev's Prolegomena to a Theory Language, in order to reach the works belonging to Algirdas Greimas, Jean-Marie Floch and Roman Jakobson. These principles and works will be the key to developing a reflection on the nature of the poetic function of language. From the works of these authors, the notions of parallelism between planes of language, linguistic sign and semi-symbolism will be explored; because they seem to be a fruitful way to understand the functioning of the poetic sign and, consequently, to provide some direction to the analysis of texts in which the poetic function of language is prominent.

KEYWORDS: Poetic function. Linguistic sign. Planes of language. Semi-symbolism. 


\section{Roman Jakobson e a noção de função poética da linguagem}

O objetivo de apreender a natureza do texto poético, para diferenciá-lo das demais formas e modalidades de discurso, fez com que se multiplicassem as vertentes de pesquisa dentro dos Estudos Literários, embora todas elas tenham, ainda que por caminhos diferentes, a mesma pretensão de apreender o fenômeno poético em sua especificidade. Tendo em vista que a semiótica francesa é uma teoria geral dos modos de significação e que tem suas convicções e hipóteses a respeito do objeto literário, vale a pena seguir seus passos para investigar sua visada própria sobre o que o caracteriza e explica. Esse interesse também cobra ainda maior sentido, quando se trata de reavaliar posturas da própria teoria semiótica sobre o objeto poético, sua natureza e modo de funcionamento.

O poético, na concepção semiótica, é compreendido essencialmente como um efeito construído por categorias responsáveis pelo sentido e se faz presente a partir da correlação direta entre componentes do plano de expressão e do plano de conteúdo do texto ou, em outras palavras, a partir da articulação do significante sonoro (ou seu representamen gráfico) com o significado, que, idealmente e em sua expressão mais completa, provoca uma ilusão referencial sobre o ouvinte/leitor (GREIMAS, 1972, p. 12). Esse mecanismo é responsável, também, pelo engendramento das conotações, que possibilitam a leitura do texto poético em várias direções isotópicas.

O grau de poeticidade de um texto varia, dessa forma, em conformidade com as correlações entre os níveis do discurso (fundamental, narrativo e discursivo) e com as homologias estabelecidas entre categorias do plano de expressão e do plano de conteúdo de que o objeto poético for capaz de 
mobilizar na semiose, como afirma Greimas (1972, p. 29), no ensaio "Por uma teoria do discurso poético"1:

Um discurso ideal, em que todos os níveis se vissem correlacionados e homologadas todas as unidades estruturais, seria talvez o mais poético: incapaz de homologar, mesmo às dimensões das frases, as estruturas da expressão e do conteúdo, ele se reduziria inevitavelmente a "um grito do coração" do poeta.

Por tratar de um objeto duplamente articulado pela junção de dois planos diferentes, a análise literária embasada em pressupostos semióticos deve procurar estabelecer uma tipologia de todas as correlações possíveis entre os planos da expressão e do conteúdo do texto (GREIMAS, 1972, p. 13). Para explicar esse fenômeno, Jakobson propôs que "o que faz de uma mensagem verbal uma obra de arte" é a dominância da função poética, que se produz quando a mensagem se debruça sobre si mesma: "O pendor para a mensagem como tal, o enfoque da mensagem por ela própria, eis a função poética da linguagem" (JAKOBSON, 1985, p. 127-128). Assim, a função poética da linguagem tem por objetivo afirmar e reafirmar sua própria beleza, dir-se-ia, de modo quase narcisista: ela se faz bela por meio da manipulação da linguagem, de modo a incutir uma dada impressão estética no destinatário. Por lidar essencialmente com a matéria verbal, "Essa função não pode ser estudada de maneira proveitosa desvinculada dos problemas gerais da linguagem, e, por outro lado, o escrutínio da linguagem exige consideração minuciosa de sua função poé-

1 Esse texto integra o livro Ensaios de semiótica poética (1972), organizado também por Greimas, que visa a compreender a natureza do texto poético sob a perspectiva semiótica. 0 volume reúne ensaios de Jean-Claude Coquet, Michel Arrivé, Claude Zilberberg, Julia Kristeva, entre outros, com estudos sobre Apollinaire, Bataille, Baudelaire, Hugo, Jarry, Mallarmé, Michaux, Nerval, Rimbaud e Roubaud. 
tica." (JAKOBSON, 1985, p. 128). Por essa razão, a semiótica francesa procura investigar a natureza do signo poético em sua dimensão biplanar, de maneira a permitir a compreensão de sua estrutura e demonstrar como é produzida essa nuance particular do sentido.

Cumpre indagar, então, de que maneira a mensagem se volta sobre si mesma e provoca o efeito de sentido poético. Jakobson já havia respondido a essa questão ao afirmar que "a função poética projeta o princípio de equivalência do eixo de seleção sobre o eixo de combinação" (JAKOBSON, 1985, p. 130). Seleção e combinação são os dois mecanismos elementares do arranjo verbal, e também aqueles responsáveis pela produtividade virtualmente infinita de enunciados da linguagem. Do repertório de vocábulos virtuais que compõem a língua, o falante seleciona, com base no princípio de equivalência, semelhança e dessemelhança, sinonímia e antonímia, aqueles que deseja utilizar e, em seguida, combina-os na cadeia verbal, com base no princípio de contiguidade. Num enunciado em que predomina a função poética, o princípio da seleção sobrepõe-se ao da combinação, de modo a criar efeitos de sentido que chamem atenção para a própria mensagem. Em um eloquente exemplo citado por Jakobson (1985, p. 128), o mestre russo menciona uma falante de inglês que costumava dizer "horrendo Henrique" (the horrible Harry, no texto original), mas que, quando foi questionada sobre a razão que a levava a selecionar o adjetivo "horrendo", dentre tantos outros de valor semântico similar (p. ex., terrível, medonho, assustador, repelente), ela não soube responder mais que afirmar que "horrendo" lhe caía melhor. Nesse caso, o princípio da seleção projetou-se intuitivamente sobre o da combinação, produzindo uma paronomásia como resultante, de forma a aproximar, no nível fônico, os vocábulos "Henri- 
que" e "horrendo" e a sugerir também uma semelhança entre as duas expressões no plano semântico, afinal "numa sequência em que a similaridade se superpõe à contiguidade, duas sequências fonêmicas semelhantes, próximas uma da outra, tendem a assumir função paronomástica, pois palavras de som semelhante se aproximam quanto ao seu significado." (JAKOBSON, 1985, p. 150-151).

Esse tipo particular de mecanismo associativo foi expresso pelo conceito de paralelismo, que consiste em sugerir que equivalências sonoras projetadas em determinada cadeia verbal implicam necessariamente equivalências semânticas; em outras palavras, estruturas forjadas por paralelismo são aquelas que emparelham uma sequência fonológica da mensagem verbal com uma sequência de unidades semânticas, ou, na terminologia de Hjelmslev (1975), elementos do plano de expressão e do plano de conteúdo de um texto dado. Acoplamentos da matéria sonora a componentes semânticos do sentido de um poema ocorrem sob a forma de rimas, paronomásia, aliteração, assonância, recorrências rítmicas etc., e, no limite, podem provocar a ilusão de que existe certa motivação entre elementos dos planos de conteúdo e de expressão:

A poesia não é o único domínio em que o simbolismo dos sons se faz sentir; é, porém, uma província em que o nexo interno entre som e significado se converte de latente em patente e se manifesta da forma mais palpável e intensa [...]. A acumulação, superior à média, de certa classe de fonemas, ou uma reunião contrastante de duas classes opostas na textura sonora de um verso, de uma estrofe, de um poema, funciona como uma "corrente subjacente de significado" [...] (JAKOBSON, 1985, p. 153). 


\section{A concepção semiótica do signo poético}

A história das concepções que tiveram em conta a natureza e funcionamento do signo poético remonta aos estudos estruturalistas iniciados por Saussure, retomados, posteriormente, por Louis Hjelmslev e desdobrados pelo semioticista Algirdas Julien Greimas. Sabe-se que os conceitos de signo, língua e linguagem receberam dos três teóricos diferentes tratamentos e concepções, embora complementares e coerentes com o pensamento estruturalista. Interessa, aqui, verificar como as noções de plano do conteúdo e plano da expressão, bem como suas subdivisões - forma e substância do conteúdo / forma e substância da expressão - propostas por Hjelmslev em seu Prolegômenos a uma teoria da linguagem (1975), podem ser pensadas no interior das concepções semióticas desenvolvidas por Greimas.

O conceito de signo, definido primeiramente por Saussure $(2003$, p. 79$)$ a partir de considerações preliminares sobre unidades do léxico das línguas naturais, pode ser extrapolado para abarcar dimensões mais amplas, como irá propor mais tarde Greimas, de forma que signo também poderá designar uma palavra, uma frase ou um discurso, na medida em que se manifesta como unidade discreta (GREIMAS, 1972, p. 16). Dessa forma, pode-se afirmar que o discurso poético é um signo complexo. Para a teoria semiótica francesa, qualquer sistema de significação é considerado uma manifestação de linguagem, a exemplo do próprio sistema da poética. Seu intuito busca compreender o funcionamento dos dois planos da linguagem propostos por Hjelmslev, quando se toma como manifestação da linguagem o sistema sígnico do poema, a fim de mostrar como os conceitos de forma/substância do conteúdo e forma/substância da expressão funcionam na produ- 
ção do signo poético, uma vez que são elas as categorias fundamentais para o estudo de uma poética da expressão.

A linguística moderna inicia-se com a formulação de Saussure (2003, p. 80) ${ }^{2}$, segundo a qual "O signo linguístico une não uma coisa e uma palavra, mas um conceito e uma imagem acústica. [...]. Esses dois elementos estão intimamente unidos e um reclama o outro.". Com esse postulado, inaugurase uma linhagem teórica que concebe o signo não mais como uma expressão de um conteúdo exterior a ele próprio, mas como um todo no qual expressão e conteúdo, ou, conforme a terminologia de Saussure, significado e significante, são solidários e inseparáveis dentro de uma relação arbitrária que se estabelece entre eles. 0 linguista suíço também estabeleceu, ademais, uma diferenciação entre língua e linguagem, segundo a qual aquela é composta somente por grandezas formais, enquanto esta abarca também grandezas físicas e não psíquicas, a que se pode denominar substância. A linguística, segundo ele, não deve se ocupar, senão, dos aspectos formais ou, em outras palavras, do signo linguístico (SAUSSURE, 2003, p. 23).

A linha de pensamento saussureana foi seguida também por Louis Hjelmslev, que avançou a construção das bases da linguística moderna, de modo a continuar a desenvolvê-la nos Prolegômenos a uma teoria da linguagem (1975). Muitas das questões já intuídas por Saussure no Curso de linguística ge-

2 Cf. o texto original, num recorte um pouco maior: "Le signe linguistique unit non une chose et un nom, mais un concept et une image acoustique. [...] Le signe linguistique est donc une entité psychique à deux faces, qui peut être représentée par la figure: fConcept/ Image acoustique‡. Ces deux éléments sont intimement unis et s'appellent l'un et l'autre." (SAUSSURE, 2005, p. 98-99). Embora o aspecto motor envolvido na articulação que produz a imagem acústica desempenhe também um papel na expressão, a edição crítica do Cours lembra que, por conceber a língua como um repositório de elementos recebidos "de fora", para Saussure a imagem articulatória do estrato acústico ficava subentendida e subordinada à representação da imagem acústica, concebida como expressão natural de uma palavra da língua virtual (ibid., p. 98). É preciso lembrar, entretanto, que a imagem articulatória passa a ser, por vezes, relevante no subsistema da Poética, como em certos casos de iconicidade e ilusão referencial produzidos em poesia. 
ral (2003), como a dos dois planos distintos que compõem a linguagem, e a presença de uma forma e uma substância que a constituem, foram sistematizadas e aprofundadas por Hjelmslev, que passa a considerar que a linguagem é constituída por dois planos homólogos, os quais ele denomina plano de conteúdo e plano de expressão, que se unem, em uma relação solidária, por meio da função semiótica, sem a qual não é possível haver linguagem: "A função semiótica é, em si mesma, uma solidariedade: expressão e conteúdo são solidários e um pressupõe necessariamente o outro. Uma expressão só é expressão porque é a expressão de um conteúdo, e um conteúdo só é conteúdo porque é conteúdo de uma expressão." (HJELMSLEV, 1975, p. 54).

Hjelmslev afirma também que tanto o plano de conteúdo quanto o plano de expressão da linguagem são constituídos, cada qual, por uma forma e uma substância e que "a distinção entre a expressão e o conteúdo, e sua interação na função semiótica, são fundamentais na estrutura da linguagem." (1975, p. 62-63). Tendo em vista que a poética é uma manifestação de linguagem, é imprescindível compreender que tipo de relação particular nela ocorre entre os planos da expressão e do conteúdo, bem como seus mecanismos internos. Ademais, é preciso também compreender a necessidade de contextualizar cada signo dentro de um sistema:

Considerado isoladamente, signo algum tem significação. Toda significação de signo nasce de um contexto, quer entendamos por isso um contexto de situação ou um contexto explícito, [...]. É necessário, assim, abster-se de acreditar que um substantivo está mais carregado de sentido do que uma preposição, ou que uma palavra está mais carregada de significação do que um sufixo de derivação ou uma terminação flexional. (HJELMSLEV, 1975, p. 50). 
Como se vê na passagem transcrita, trata-se de uma decorrência e ampliação conceitual daquilo a que Saussure chamou valor linguístico. Os signos constituem um sistema que será determinante para seu processo de significação, portanto, o sentido de cada um deles não é atribuído apenas em relação a sua constituição interna, mas em decorrência do valor que ele assume em oposição aos demais signos da língua.

Antes, porém, de verificar como conteúdo e expressão manifestam-se nos domínios do texto poético, é conveniente lembrar as importantes distinções propostas por Hjelmslev para explicar como eles funcionam no sistema da língua: 1) a substância do conteúdo pode ser definida como sentido geral (grandeza amorfa / massa do pensamento) que é enformado na manifestação linguística pela forma do conteúdo (conjunto de traços sêmicos que a recortam e organizam), 2) a substância da expressão corresponde àquilo que Saussure chamava som material (2003, p. 80), isto é, os sons físicos e articulados produzidos pelo aparelho fonador; a forma da expressão, por sua vez, corresponde ao conjunto de fonemas sobre os quais se organiza a estrutura fonológica de uma língua.

Convém relembrar que Hjelmslev, tal qual Saussure, entende por signo apenas os aspectos formais da linguagem, já que os aspectos da substância são ejetados da estrutura da língua, de forma que "[...] parece mais adequado utilizar a palavra signo para designar a unidade constituída pela forma do conteúdo e pela forma da expressão [...]" (HJELMSLEV, 1975, p. 62). Essa definição, segundo ambos, é suficiente para uma descrição linguística do texto, porém, quando se tem em vista o objeto poético, o sistema da poética sobrepõe-se ao sistema da língua ou, em outras palavras, o sistema da língua é recodificado pelo sistema da poética, originando, por sua vez, o signo poético - ou o signo em estado de apreensão poética 
- de modo que a substância, que não participa do objeto de estudo da linguística, torna-se potencialmente implicada no estudo da expressão poética.

É, portanto, na junção entre a forma e a substância da linguagem que se estrutura o signo poético, cuja forma do conteúdo se constitui na relação entre os signos (isotopias ${ }^{3}$ ), e a forma da expressão, no ritmo do poema, que advém, sobretudo, do metro, das cesuras, das aliterações, assonâncias etc. Interessa, portanto, para o estudo da poética, uma teoria geral da significação que se ocupe das homologias entre os dois planos da linguagem.

Ainda no que respeita a essas questões, não se pode esquecer a discussão iniciada por Hjelmslev, em seus Prolegômenos a uma teoria da linguagem (1975, p. 121), sobre as semióticas conotativas em que, por oposição às semióticas denotativas, nenhum dos dois planos (expressão e conteúdo) é uma semiótica. Semióticas conotativas são aquelas cujo plano da expressão por si mesmo constitui uma semiótica, ou seja, trata-se de uma semiótica cujo plano de expressão é constituído pelo plano de expressão e o plano de conteúdo de uma outra semiótica. Sendo assim, o que possibilita a existência da conotação é o fato de que ela se institui sob um código precedente e não pode ser veiculada antes de o conteúdo primeiro ter sido denotado. É graças a esse mecanismo que é possível, por exemplo, quer a existência do fenômeno da polissemia, quer o da metáfora, que se constitui como figura de linguagem dominante na função poética.

Por isso, é fundamental à análise literária o estudo do plano do conteúdo e do plano de expressão, de maneira a 
identificar processos de conotação e explorar homologias instauradas no e pelo texto, a fim de desvendar os mecanismos pelos quais se produz sua poeticidade. Tal necessidade havia sido prevista já pelo próprio Greimas, na década de 70, com a organização do volume Ensaios de semiótica poética (1972), de forma que, embora a teoria semiótica ainda não tivesse criado uma metodologia para o estudo dos isomorfismos interplanares, sua necessidade já havia sido percebida e o terreno das discussões acerca das formas de estudá-lo já estava sendo preparado. Ao formular o método de análise denominado percurso gerativo do sentido, Greimas não tinha como princípio ignorar a correlação entre o conteúdo e a expressão, tampouco negar a solidariedade que se estabelece entre os dois planos no ato da comunicação:

Les structures de la signification, telles que nous venons de les définir, se manifestent [...] dans la comunication. La comunication, en effet, réunit les conditions de leur manifestation, car c'est dans l'acte de comunication, dans l'événement-communication, que le signifié retrouve le signifiant. (GREIMAS, 1966, p. 30).

Por constatar, porém, que a linguagem somente se vale de isomorfismos entre expressão e conteúdo em contextos específicos - como no caso da linguagem poética - acreditava o semioticista lituano que seus dois planos, para fins didáticos e unicamente de análise, deveriam ser estudados separadamente:

Il faut d'abord constater l'absence d'isomorphie entre les deux plans du signifiant et du signifié; les unités de communication des deux plans ne sont pas équidimensionnelles. [...]. L'analyse des deux plans doit donc être menée, bien que par les mêmes méthodes, séparément, et elle devra viser à établir l'existence 
des phèmes pour le signifiant, et des sèmes pour le signifié, unités minimales de deux plans du langage. (GREIMAS, 1966, p. 30).

Estudá-los separadamente, entretanto, não é o mesmo que ignorar as relações existentes entre os dois planos, como reafirma Greimas, ainda em Sémantique structurale, ao afirmar que, embora seja necessário separar expressão e conteúdo com a finalidade de progredir na análise, é preciso reter a possibilidade e a necessidade de utilizar seja o significado para o estudo do significante seja do significante para o estudo do significado: “Ce qu'il faut en retenir, c'est la possibilité et la nécessité de se servir du signifié pour l'étude du signifiant et du signifiant pour celle du signifié. C'est d'ailleurs le rôle que nous avons assigné aux termes-objets." (GREIMAS, 1966, p. 31).

Quando se refere, no entanto, à linguagem poética, interesse específico deste artigo, Greimas reconhece e aponta a presença dos isomorfismos entre expressão e conteúdo, de modo que, nesses domínios, não vê possibilidade de apartar os planos no processo de análise:

Reconhecendo que o discurso poético é na realidade um discurso duplo que projeta as suas articulações simultaneamente nos dois planos - no da expressão e no do conteúdo - ela ${ }^{4}$ deverá elaborar um aparato conceitual, susceptível de fundamentar e de justificar os processos de reconhecimento das articulações desses dois discursos. [...] Dispondo de diversos níveis linguísticos homogêneos em cada um dos dois planos da linguagem, a semiótica poética deve estar capacitada a estabelecer uma tipologia de correlações possíveis entre os planos da expressão e do conteúdo e, consequente- 
mente, a instituir uma tipologia de objetos poéticos calcada na atribuição destes ou daqueles níveis linguísticos do discurso poético, tendo em vista a sua correlação. (GREIMAS, 1966, p. 12-13, grifo do autor).

É, portanto, somente a partir da análise dos isomorfismos entre expressão e conteúdo que o fenômeno poético pode ser devidamente apreendido. Greimas e Courtés (2008, p. 275) assim definem o conceito de isomorfismo:

Isomorfismo é a identidade formal de duas ou mais estruturas que dependem de planos ou de níveis semióticos diferentes, reconhecível em razão da homologação possível das redes relacionadas que os constituem. Assim, um isomorfismo pode ser reconhecido, por exemplo, entre as articulações do plano de expressão e do conteúdo homologando: femas : semas :: fonemas: sememas :: sílabas : enunciados semânticos.

Como se percebe, a noção de isomorfismo corresponde, em grande medida, ao conceito de paralelismo desenvolvido por Jakobson. Trata-se de homologações e acoplamentos que ocorrem entre as categorias do plano de conteúdo e do plano de expressão da linguagem. Na esfera do objeto literário, tais isomorfismos adensam a poeticidade do texto: por exemplo, a matéria fônica do plano de expressão é organizada de maneira a que os signos presentes no poema sejam aproximados e passem a confluir na mesma direção, assegurando e reforçando, por meio do plano de expressão, a isotopia figurativa delineada no plano de conteúdo, como se pode observar na letra da canção "A Rita”, de Chico Buarque: 


\section{A Rita}

A Rita levou meu sorriso

No sorriso dela

Meu assunto

Levou junto com ela

0 que me é de direito

E arrancou-me do peito

E tem mais

Levou seu retrato, seu trapo, seu prato

Que papel!

Uma imagem de são Francisco

E um bom disco de Noel

A Rita matou nosso amor

De vingança

Nem herança deixou

Não levou um tostão

Porque não tinha não

Mas causou perdas e danos

Levou os meus planos

Meus pobres enganos

Os meus vinte anos

0 meu coração

E além de tudo

Me deixou mudo

Um violăo

(BUARQUE, 2007, p. 143, grifo nosso).

O enunciador do texto recorre à figura de linguagem denominada paronomásia para potencializar os efeitos de sentido pretendidos pela letra da canção. Trata-se de figura muito uti- 
lizada em poesia, de modo que até mesmo dicionários de uso do português, como o Houaiss (2002, s.v. paronomásia), registram que paronomásia corresponde à figura de estilo que extrai expressividade da combinação de palavras que apresentam semelhança fônica (e/ou mórfica), mas possuem sentidos diferentes $^{5}$. Tal recurso pode ser verificado em todo o texto (vejamse os grifos), mas atinge o ápice no grupo de versos: "Levou seu retrato, seu trapo, seu prato" e "Mas causou perdas e danos / Levou os meus planos / Meus pobres enganos / Os meus vinte anos". Vocábulos com sentidos diferentes, mas semelhantes foneticamente, são reunidos, por meio do processo de seleção e combinação realizado pelo enunciador, no mesmo sintagma frasal, de modo que eles passam, em virtude da materialidade fônica do plano de expressão, a confluir na mesma direção, homologando-se à isotopia desenvolvida no plano de conteúdo. 0 processo paronomástico faz com que aquelas palavras com sentidos diferentes produzam o efeito de similitude semântica quando reunidas, como muito bem evidencia Jakobson (1985, p. 72): "A semelhança fonológica é sentida como um parentesco semântico. 0 trocadilho, ou, para empregar um termo mais erudito e talvez mais preciso, a paronomásia, reina na arte poética".

O conjunto de expressões paronomásticas retrato, trapo e prato, bem como aquele constituído pelos vocábulos danos, planos, enganos e anos constroem sintagmas que estabelecem uma isotopia de perda, configurada no plano de conteúdo do texto. No caso específico do segundo grupo paronomástico, observa-se que o vocábulo anos está contido na estrutura morfo-fonética das expressões que o precedem -

5 Dicionários especializados dirão também que parônimos são palavras com sonoridade semelhante, bem como que seu emprego em poesia é capaz de produzir resultados muito felizes a partir do simples jogo de significantes, mas também que não consiste em mero artifício lúdico, podendo produzir significação sutil por meio das relações que logra estabelecer (cf. POUGEOISE, 2006, p. 353, s.v. Paronomase). 
danos, planos e enganos - de modo a reiterar, pela recorrência da materialidade fônica, a substância do conteúdo, qual seja, o tempo empenhado, vertido e perdido em uma relação fracassada. Os procedimentos poéticos aqui explicitados, alcançados por meio de operações paralelísticas, constituem, assim, aquilo a que Greimas e Courtés chamam isomorfismo.

Dentro da categoria denominada isomorfismo, há, ainda, a noção de iconicidade, que corresponde, de igual maneira, ao resultado da homologação entre plano de conteúdo e plano de expressão do texto, alcançada também pelo processo do paralelismo, mas, nesse caso, com a finalidade de provocar uma ilusão referencial no leitor ou, em outras palavras, a impressão de realidade diante daquilo que é lido:

Esta pode ser definida como sendo o conjunto de procedimentos mobilizados para produzir efeito de sentido de 'realidade', aparecendo assim como duplamente condicionada pela concepção culturalmente variável da 'realidade' e pela ideologia realista assumida pelos produtores e usuários desta ou daquela semiótica. (GREIMAS; COURTÉS, 2008, p. 223).

Na medida em que o procedimento de iconização remete à ilusão referencial, ele se situa também no interior do percurso gerativo do sentido, mais especificamente na última etapa do nível discursivo, e remete ao processo de figurativização, que, segundo Denis Bertrand (2003, p. 154):

[...] foi estendido a todas as linguagens, tanto verbais quanto não verbais, para designar esta propriedade que elas têm em comum de produzir e restituir parcialmente significações análogas às de nossas experiências perceptivas mais concretas. A figuratividade permite, assim, localizar no discurso esse efeito de sentido particular que consiste em tornar sensível a realidade sensível [...] 
A figurativização é, pois, o procedimento que reveste o discurso para que ele se aproxime o máximo possível do referente. 0 processo de sua constituição contempla, porém, dois níveis diversos: a figuração, momento em que os temas são convertidos em figuras, e, quando logra chegar a tanto, também o da iconização, que toma as figuras já constituídas e as dota de um revestimento particularizante (realizado pelos procedimentos expressivos quando homologados ao conteúdo), suscetíveis de produzir uma ilusão referencial (GREIMAS; COURTÉS, 2008, p. 223), ou seja, "essa iconicidade, portanto, nada mais é do que uma forma dentre outras possíveis de explorar componentes figurativos da expressão linguística." (BERTRAND, 2003, p. 208).

Para melhor compreender o funcionamento da iconicidade, bem como o comportamento dos planos da linguagem, quando motivados no momento da semiose (manifestação), segue o exemplo da letra da canção Cajuína (1989), de Caetano Veloso:

Existirmos: a que será que se destina?

Pois quando tu me deste a rosa pequenina

Vi que és um homem lindo e que se acaso a sina

Do menino infeliz não se nos ilumina

Tampouco turva-se a lágrima nordestina

Apenas a matéria vida era tão fina

E éramos olharmo-nos intacta retina

A cajuína cristalina em Teresina

(VELOSO, 1989).

No plano do conteúdo, a substância, que é o questionamento da miséria humana e da condição e fragilidade da própria existência, está organizada no texto por meio de uma sintaxe e de uma semântica narrativas, bem como por meio 
da instalação de figuras no discurso - rosa pequenina, sina, menino infeliz, lágrima nordestina, matéria vida, fina, intacta retina, cajuína, Teresina - que compõem uma isotopia enformadora da substância primeira. No nível da expressão, a materialidade fônica da substância sonora é, por sua vez, enformada por uma cadeia de fonemas em que se destaca o som articulado da vogal alta e fechada / i /:

Existịmos: a que [ki $\mathbf{i}]$ será que [ki $\mathbf{i}]$ se [si] destinna?

Poịs quando tu me [mi] deste [d3s'ti] a rosa pequenina

Ví que [kí] és um homem lindo e que [ki $]$ se [sí] acaso a sina

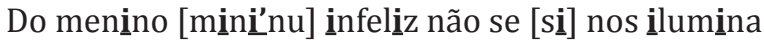
Tampouco turva-se [si] a lágrimma nordestina Apenas a matéria vịda era tão fịna E [i] éramos olharmo-nos intacta retina A cajuína cristalinna em [ịm] Teresina (VELOSO, 1989).

No texto, foram destacados também os /i/s fonéticos (entre colchetes) para que se perceba que a densidade de ocorrência é ainda maior do que permite vislumbrar sua representação gráfica. A cadeia sonora é distribuída em versos dodecassílabos, de modo geral com acentuação nas sílabas pares $^{6}$ (Pois quando tu me deste a rosa pequenina) e esquema de rima uniforme, que, segundo José Miguel Wisnick (1996, p. 205), muito se aproximam do ritmo popular do xote nordestino.

Na letra da canção "Cajuína” (1989), de Caetano Veloso, a reverberação sonora do fonema /i/, vogal constrita, de timbre agudo e fechado, bem como de grafismo longilíneo e

6 Com exceção do penúltimo verso. Note-se, entretanto, que o papel estabilizador conferido pela música que enforma a letra, tende a destacar e estabilizar também acentos secundários de palavra nas sílabas pares, como ocorre na sílaba pe- de "pequenina". 
estreito, homologa-se à substância do conteúdo, qual seja, a fragilidade da existência, (WISNIK, 1996, p. 204-205; THAMOS, 2002, p. 116), que pode ser representada/refigurada pela imagem da vida que se sustém por um fio - figura prefigurada já gráfica e foneticamente na sobrecarga de /i/s ali presentes - potencializando a angústia disforizante que se estende para o campo de presença do discurso. Nesse sentido, é curioso ainda observar que a angústia ${ }^{7}$ apresenta como principal sintoma o estreitamento de órgãos como coração, peito, garganta, entre outros ${ }^{8}$; e tal sensação é mimetizada por meio do trabalho meticuloso e particular com a sonoridade do signo poético.

Observa-se, assim, que a substância da expressão, excluída do objeto de estudo da linguística - a língua - passa não apenas a ser detentora de sentido no poema, como a ser fundamental para o efeito de sentido poético, tornando-se, dessa maneira, um dado formal no âmbito dos Estudos Literários, como já previa o próprio Greimas (1972, p. 12):

O efeito de sentido (poético) surge aqui como um efeito dos sentidos: o significante sonoro - e gráfico, em menor proporção - entra em jogo para conjugar suas articulações com as do significado, provocando com isto uma ilusão referencial e incitando-nos a assumir como verdadeiras as proposições emitidas pelo discurso poético, cuja sacralidade fica assim fundamentada em sua materialidade.

7 Vale lembrar, aqui, que esse termo é etimologicamente ligado ao substantivo latino angustia- (passagem estreita) e ao adjetivo angusto-/-a- (estreito, apertado, constrito) (cf. GLARE, 1968, p. 130-131, s.v. angustia,-ae e angustus,-a,-um) que, por sua vez, provém do antigo verbo angerre (estreitar, apertar, cerrar a garganta) (cf. ERNOUT; MEILLET, 1959, p. 33, s.v. ango).

8 Como bem descreve Hannah Arendt (2001, p. 17) em uma de suas cartas amorosas direcionadas a Heidegger: "Mas também é possível que a nostalgia tenha aberto seus reinos [...] e que a angústia tenha fechado tudo pesadamente, tenha-lhe cortado a respiração livre, deixando-a paralisada em meio à sensação de estar sendo caçada.”. 


\section{Semissimbolismo e signo poético}

A preocupação de Greimas com isomorfismos entre conteúdo e expressão torna forçoso admitir que quedam sem efeito possíveis críticas ${ }^{9}$ ao percurso gerativo do sentido, já que, mesmo sem encontrar solução definitiva para o problema, o semioticista lituano previa a necessidade de dedicar-se também ao plano de expressão do objeto poético. 0 método gerativo surgiu quando a semiótica era ainda uma ciência incipiente e muito faltava para seu mais cabal desenvolvimento, até que pudesse abarcar por completo o estudo do texto poético, assim o estudo sobre o plano da expressão, que não foi privilegiado no princípio dos estudos semióticos, acabou por surgir posteriormente, sobretudo a partir das ideias de Jean-Marie Floch e sua teoria do semissimbolismo, essencial para os estudos da poética sob uma perspectiva semiótica, especialmente pela atenção voltada aos acoplamentos entre os planos da linguagem. Floch (1985) desenvolveu a teoria do semissimbolismo em Petites mythologies de l'oeil \& de l'esprit: por une sémiotique plastique, mais especificamente no capítulo intitulado "Sémiotique plastique \& communication publicitaire" (FLOCH, 1985, p. 139-186), em que ele se debruça sobre a investigação de dois textos publicitários com apelo visual: as campanhas da marca de cigarro News e do curativo autocolante Urgo, que mobilizam,

9 Tais críticas consistem geralmente no fato de a semiótica ter-se ocupado quase exclusivamente com o estudo do percurso gerativo do sentido, que se dedica a esgotar as possibilidades de compreender a articulação de sentidos do plano de conteúdo de qualquer objeto de significação. A crítica propriamente dita concentra-se em que isso vai de encontro à basilar afirmação de Hjelmslev (1975, p. 77), segundo a qual plano de conteúdo e plano de expressão não devem, sob nenhuma hipótese, ser separados. Desdobramentos ulteriores e avanços da teoria semiótica, porém, permitiram desenvolver o conceito de semissimbolismo, cujo lugar e propósito são precisamente resgatar a necessidade de compreender plano de conteúdo e plano de expressão como grandezas que se pressupõem mutuamente, o que realiza o projeto do postulado hjelmsleviano e põe fim à aparente contradição. 
no processo de significação, textos verbais e não verbais, necessitando, por isso, de uma semiótica que priorize os sistemas semissimbólicos sincréticos.

Os estudos de Floch, embora tenham sido inicialmente desenvolvidos para a semiótica visual, mostram-se úteis também para as investigações que recaem sobre o texto poético verbal, visto que o semissímbolo constitui matéria essencial na linguagem literária. É muito importante, no entanto, que se compreendam as noções linguísticas de signo e símbolo para adentrar a esfera do semissímbolo e verificar de que forma esse procedimento atua e tensiona os procedimentos poéticos do texto literário.

Em sua acepção saussureana, o signo linguístico é o vínculo de união necessária e indissociável entre um conceito e uma imagem acústica ou, em outras palavras, entre um significado e um significante, e esses dois elementos aparecem intimamente unidos, de modo que um clama a presença do outro. Tanto o conceito quanto a imagem acústica são entidades completamente psíquicas e, portanto, formais, de modo que existem apenas dentro do universo da linguagem. 0 objeto real, dessa forma, não corresponde ao conceito, assim como o som não corresponde à imagem acústica, como muito bem evidencia o linguista suíço ao afirmar que "O signo linguístico une não uma coisa e uma palavra, mas um conceito e uma imagem acústica." (SAUSSURE, 2003, p. 80).

A relação que os une - e esse é um dos fundamentos necessários para compreender o semissimbolismo — é inquestionavelmente arbitrária: "O laço que une o significante ao significado é arbitrário ou então, visto que entendemos por signo o total resultante da associação de um significante com um significado, podemos dizer simplesmente: 'o signo linguístico é arbitrário.'” (SAUSSURE, 2003, p. 81). A noção de 
arbitrariedade pauta-se, assim, no postulado de que não há motivação alguma na relação que une o significante ao significado: “[...] o significante é imotivado, isto é, arbitrário em relação ao significado com o qual não tem nenhum laço natural na realidade." (SAUSSURE, 2003, p. 83).

O símbolo, por sua vez, diferentemente do signo, mantém um grau de motivação natural ${ }^{10}$ entre as partes que o constituem: "O símbolo tem como característica não ser jamais completamente arbitrário; ele não está vazio, existe um rudimento de vínculo natural entre o significante e o significado." (SAUSSURE, 2003, p. 82); ou, nas palavras de Lopes (1977, p. 44), “Os símbolos são objetos materiais que representam noções abstratas.".

Saussure (2003, p. 82) recorre à balança, símbolo da justiça, para exemplificar a questão: "O símbolo da justiça, a balança, não poderia ser substituído por um objeto qualquer, um carro, por exemplo". A balança, dessa forma, não poderia ser substituída por um carro, uma máquina de escrever ou uma casa, pois há um vínculo natural não arbitrário, uma motivação - empreendida pelas conotações sociais presentes na cultura, é claro - que a associa à própria ideia de justiça. De acordo com o dicionário Houaiss (2002, s.v. balança), a balança consiste em um instrumento que serve para pesar objetos diversos, constituído por uma haste vertical, na qual repousa um travessão móvel com dois pratos pendentes, um em cada extremidade. Em virtude de sua composição, a balança remete à ideia de equilíbrio e imparcialidade, razão pela qual é associada culturalmente aos julgamentos e, consequentemente,

10 Emprega-se "natural", aqui, na mesma direção com que o fez Saussure que, ao falar do símbolo, denunciou-lhe um 'rudimento de vínculo' com certa motivação natural que une significante e significado, ou seja, natural aqui significa aquilo em que há ainda um resíduo de motivação entre o que se convenciona representar com uma determinada forma e o representado que mantém alguma relação com o mundo natural. 
à justiça. 0 símbolo, no entanto, não abrange completamente todas as noções do conteúdo simbolizado, como demonstra Lopes (1977, p. 44) no excerto que segue:

A representação do símbolo é sempre deficiente ou inadequada parcialmente em relação ao conjunto das noções simbolizadas, porque o símbolo é uma parte do todo que é o conteúdo abstrato com o qual ele se relaciona (REZNIKOV, 1972, p. 166). Assim, o conceito de justiça é muito mais amplo do que o conteúdo abrangido pela balança, que recorda apenas um dos atributos da justiça, a igualdade [...].

A motivação é, assim, a instância fundamental que diferencia o signo linguístico do símbolo. Enquanto aquele se define pela noção de arbitrariedade entre as partes que o constituem - significado e significante - este se constitui justamente pela motivação natural entre o símbolo e o conteúdo por ele simbolizado. Entre os extremos dessas duas categorias, porém, há ainda uma terceira - a que mais interessa aqui - chamada por Floch de semissímbolo, que apresenta traços estruturais tanto do signo quanto do símbolo, como bem explica Silva (1995, p. 65):

'Atualidade sígnica' quer dizer signo em que não há, aparentemente, nenhuma relação de conformidade entre plano de expressão e plano de conteúdo, sendo o sígnico, por excelência, da ordem daquilo que Saussure chamaria de arbitrário, enquanto o símbolo seria um signo em que haveria relação de conformidade entre expressão e conteúdo; do cruzamento desses dois surge o semi-símbolo, com a introdução de alguma parcela de motivação: o primeiro perde em não conformidade e o segundo, em conformidade. Daí resulta o semi-símbolo, o signo por excelência da expressão artística. 
O texto poético é constituído por signos linguísticos, não por símbolos, portanto, a relação de arbitrariedade não pode deixar de existir. Dentro do contexto específico do poema, no entanto, os signos linguísticos são manipulados de maneira tal que se cria artificialmente a impressão de motivação, ao homologar o plano de expressão ao plano de conteúdo do texto no momento da manifestação, como aponta Fiorin (2001, p. 14):

No âmbito da arte da palavra, o sonho dos poetas é anular a "arbitrariedade do signo lingüístico, para que, operando com recursos fônicos, possam fazer que a expressão não somente seja um suporte do conteúdo mas também o mostre, com a homologia entre os dois planos da linguagem.

É justamente essa relação entre conteúdo e expressão forjada pelo poeta que traduz o conceito de semissimbolismo. Será prudente sublinhar que a motivação não ocorre de forma natural como no caso do símbolo per se, mas de modo artificial e vez por vez, com a finalidade de criar determinado efeito de sentido no ato da leitura, por isso, apenas dentro de determinado contexto, um determinado signo ou conjunto de signos atinge o estatuto de semissímbolo. Se o contexto se modifica, não há mais garantia de que a relação semissimbólica se preserve.

São os procedimentos da poética os responsáveis por provocar a conversão do signo em semissímbolo, e, dentre eles, o que mais reclama atenção é o paralelismo jakobsoniano, de que já se falou aqui anteriormente, cujo processo de seleção e combinação das palavras visa a produzir de forma artificial uma ilusão tal que leva a crer que há certo grau de motivação entre conteúdo e expressão (BENITES, 2008, p. 141), e que, consequentemente, é também responsável pelo efeito de poeticidade que emana do texto. 
A noção de semissimbolismo pouco se distancia da de isomorfismo, explicitada no verbete do Dicionário de Semiótica (2008), já que, em ambas as concepções, subjaz o importante conceito de homologia entre as categorias do plano de expressão e do plano de conteúdo do texto. 0 semissimbolismo, contudo, acresce ao conceito de isomorfismo a discussão entre "naturalidade" versus "artificialidade" na motivação sígnica, fundamental para que não surjam dúvidas a respeito da estrutura do signo linguístico, que tem como base necessária e inapelável a arbitrariedade.

\section{Considerações finais}

O engendramento da função poética no momento da semiose apresenta particularidades que tornam sua composição interna, bem como os efeitos produzidos no destinatário da mensagem, diferentes das demais manifestações da linguagem. A linguagem da comunicação corrente tem um objetivo claro que deve ser atingido: transmitir uma mensagem verbal desejada ou, em outras palavras, levar um interlocutor a compreendê-la; se empregada, porém, em favor da própria mensagem, sem visar a um objetivo pragmático, imediato e "utilitário", tem-se a função poética da linguagem. Procurou-se, ao longo deste artigo, compreender a estrutura do signo poético por meio de uma reconsideração histórica, mas, sobretudo, conceitual, dos princípios teóricos da semiótica francesa, que se presta a compreender o funcionamento da significação em suas mais diversas esferas, incluindo-se aí a do texto poético. Portanto, as noções de função poética, paralelismo, semióticas conotativas, signo linguístico, planos da linguagem e semissimbolismo colocam-se como um caminho possível para compreender o funcionamento do signo poético 
e, consequentemente, para a análise de textos que apresentem como particularidade o predomínio dessa função, como Jakobson já apontou em inúmeros textos (q. v., p. ex., "O Dominante", JAKOBSON, 2002, p. 511-518).

Octávio Paz, em seu ensaio crítico O Arco e a Lira (1982), desenvolveu a ideia de que a disjunção primeira do ser humano com o real estabelece-se a partir do momento em que o homem adentrou o universo da cultura por meio da linguagem, como se pode verificar no seguinte excerto: "O homem é homem graças à linguagem, graças à metáfora original que o fez ser outro e o separou do mundo natural. 0 homem é um ser que se criou ao criar uma linguagem. Pela palavra, o homem é uma metáfora de si mesmo." (PAZ, 1982, p. 4142). Nessa mesma linha de pensamento, é possível concluir que é a linguagem que separa o sujeito do contato original com o mundo, mas, ao mesmo tempo, é ela quem estabelece a única ponte com o real. E da impossibilidade de reconciliação do homem com o mundo, surge o poema que, por sua vez, é consequência da separação entre o indivíduo e a unidade primordial, mas, também, a tentativa maior de unir o que dele foi apartado, pois, ainda em conjunção com o pensamento de Paz, é preciso considerar que "o poema continuará sendo um dos poucos recursos do homem para ir além de si mesmo, ao encontro do que é profundo e original." (PAZ, 1982, p. 45). Na tentativa de regressar ao mundo natural, o poema mobiliza todas as potencialidades da linguagem e, dentre elas, também a substância da expressão, a materialidade fônica, que recupera a música do mundo, perdida no ato da separação homem/mundo natural, (re)criando para o sujeito destinatário a ilusão de estar diante de um real que lhe foi subtraído desde o contato primeiro com a linguagem. 


\section{REFERÊNCIAS}

ARENDT, H.; MARTIN, H. Correspondência 1925/1975. In LUDZ, U. (Org.). Tradução de M. A. Casa Nova. Rio de Janeiro: Relume Dumará, 2001.

BENITES, M. V. Aracne e Palas: uma trama de sentido estudo semiótico de Metamorfoses, de Ovídio (Liber VI, 01-145). 2008. 209 f. Dissertação (Mestrado em Estudos Literários) - Faculdade de Ciências e Letras, Universidade Estadual Paulista, Araraquara, 2008.

BERTRAND, D. Caminhos da semiótica literária. Bauru: EDUSC, 2003.

BUARQUE, C. Tantas Palavras. São Paulo: Companhia das Letras, 2007.

ERNOUT, A. ; MEILLET, A. Dictionnaire étymologique de la langue latine. Histoire des mots. 4 éme éd. Paris: Klincksieck, 1959.

FIORIN, J. L. Astúcias da enunciação. São Paulo: Ática, 2001. FLOCH, J.-M. Petites mythologies de l'oeil et de l'esprit. Paris-Amsterdam: Éditions Hadès-Benjamins, 1985.

GLARE, P. G. W. (Ed.). Oxford latin dictionary. Oxford: Clarendon Press, 1968.

GREIMAS, A. J. et alii. Ensaios de semiótica poética. São Paulo: Cultrix, 1972.

. Sémantique structural. Paris: Librairie Larousse, 1966.

GREIMAS, A. J.; COURTÉS, J. Dicionário de semiótica. 
Tradução de A. D. Lima et alli. São Paulo: Cultrix, 2008.

HJEMSLEV, L. Prolegômenos a uma Teoria da Linguagem. Tradução de J. Teixeira Coelho Netto. São Paulo: Perspectiva, 1975.

HOUAISS, A. Dicionário eletrônico Houaiss da língua portuguesa. São Paulo: Objetiva, 2002.

JAKOBSON, R. "O dominante". In LIMA, L. C. Teoria da literatura em suas fontes. Rio de Janeiro: Civilização brasileira, 2002. p. 511-518.

Linguística e comunicação. 6. ed. Tradução de I. Blikstein e J. P. Paes. São Paulo: Cultrix, 1985.

LOPES, E. Fundamentos da linguística contemporânea. 2. ed. São Paulo: Cultrix, 1977.

PAZ, 0. 0 arco e a lira. 2. ed. Tradução de O. Savary. Rio de Janeiro: Nova Fronteira, 1982.

POUGEOISE, M. Dicionnaire de poétique. Paris: Belin, 2006. SAUSSURE, F. de. Cours de linguistique générale. Éd. critique préparée par T. de Mauro. Paris: Payot, 2005.

. Curso de linguística geral. São Paulo: Cultrix, 2003.

SILVA, I. A. Figurativização e metamorfose: o mito de narciso. São Paulo: Editora da Universidade Estadual Paulista, 1995.

THAMOS, M. “Figuratividade na poesia”. In LEITE, S.; BALDAN, M. (Org.). Itinerários: revista de literatura. Araraquara: Gráfica Unesp, 2002. p. 101-118.

VELOSO, C. “Cajuína”. In Cinema transcendental. Rio de Janeiro: Polygram Philips, 1989. 1 CD (Faixa 9; Encarte). 
Marcela Ulhôa Borges MAGALHÃES, João Batista Toledo PRADO

WISNIK, J. M. "Cajuína transcendental". In BOSI, A. (Org.). Leitura de poesia. São Paulo: Ed. Ática, 1996. p. 193-219.

Artigo recebido em março de 2015 e aprovado em junho de 2015.

Disponível em: http://seer.fclar.unesp.br/casa 